\title{
Uterine and ovarian parameters in healthy North Indian girls from 5 to 16 years by ultrasonography
}

Parametry macicy i jajników u zdrowych dziewcząt w wieku 5-16 lat z Północnych Indii w ultrasonografii

\author{
1,Mayank Dixit, 'Vijay Jaiswal, ${ }^{1}$ Yasmeen Usmani, ${ }^{3}$ Rachna Chaudhary \\ ${ }^{1}$ Paediatrics and Paediatric Endocrinology, Lala Lajpat Rai Memorial (LLRM) Medical College, Meerut, India \\ ${ }^{2}$ Radiology, Lala Lajpat Rai Memorial (LLRM) Medical College, Meerut, India \\ ${ }^{3}$ Obstetrics and Gynaecology, Lala Lajpat Rai Memorial (LLRM) Medical College, Meerut, India
}

\begin{abstract}
Introduction: Knowledge of uterine and ovarian growth patterns during early age and puberty helps in investigating disorders of pubertal development i.e. precocious puberty, premature thelarche, or pubarche. There is a paucity of data for uterine and ovarian parameters.

Aim of the study: The aim of this study is to present normative data for Uterine length, Mean ovarian volume (MOV), and fundo cervical ratio (FCR) from 5 to 16 years in healthy girls from north India and to correlate these parameters with age, weight, height, and pubertal Tanner staging.

Material and methods: A cross-sectional observational study was performed on 130 healthy girls age 5 to 16 years. Age, anthropometric parameters were measured and the pubertal stage was categorized using Tanner staging. All subjects underwent pelvic ultrasonography for the measurement of uterine and ovarian parameters.

Results: Normative data of uterine length, MOV, and FCR were presented as mean, SD, median, and 95\% confidence interval as per age and Tanner stage. A progressive increase in uterine length, MOV \& FCR was observed with increasing age, weight, height, and Tanner stage $(p<0.001)$. A sudden significant increment in uterine length and MOV was observed between the age of $11-12$ and $12-13$ years $(p<0.001)$. Uterine length of $<4 \mathrm{~cm}$, MOV $<2 \mathrm{~cm}^{3}$ and FCR $<1$ were specific to identify pre-pubertal girls.

Conclusions: Normative data of uterine and ovarian parameters generated in our study by ultrasonography would be useful for screening girls with abnormalities of pubertal development.
\end{abstract}

Key words:

ultrasonography, fundo cervical ratio, mean ovarian volume, uterine length.

\section{Introduction}

Puberty is a transitional period between childhood and adulthood, during which a growth spurt occurs, secondary sexual characteristics appear, internal reproductive organs develop, and fertility is achieved. With the increasing global trend of precocious puberty in girls, knowledge about normative growth and the developmental pattern that take place in the female internal reproductive organs, i.e. uterus and ovaries, during early age and puberty using ultrasonography is essential for investigating disorders of pubertal development, i.e. precocious puberty, premature thelarche, or premature pubarche [1]. Ultrasonography is a rapid, safe, non-invasive, painless, and accurate method to monitor the growth pattern of the female reproductive system [2, 3]. Several previous studies have attempted to assess the development of the uterus and ovaries in the normal population throughout childhood and adolescence and to provide reference values. However, there is a wide variation in the results of these studies, which can be attributed to different geographical locations, the small size of study populations, limited age range, and limited statistical analysis [4-14]. We, therefore, designed a study to present normative data for uterine length, mean ovarian volume (MOV), and fundo-cervical ratio (FCR) from 5 to 16 years in healthy girls from north India, and to correlate these parameters with chronological age, weight, height, and Tanner pubertal staging. 


\section{Material and methods}

\section{Study structure and population}

A cross-sectional study was performed on 130 girls aged 5 to 16 years, who accompanied patients attending outpatient clinics of a tertiary care medical college hospital of northern India. Girls were considered as normal if their height and weight were between the $3^{\text {rd }}$ and $97^{\text {th }}$ percentile as per IAP growth charts. Girls with height and weight less than $3^{\text {rd }}$ and or more than the $97^{\text {th }}$ percentile as per IAP growth charts and who presented with gynaecological or endocrine disorders, chronic disease, urogynaecological malformation, or pelvic pain, and those who had the uterus or ovaries surgically removed were excluded from the study. All healthy, normal girls fulfilling the inclusion criteria were enrolled and allocated into groups according to age and Tanner pubertal staging. The study was approved by the institutional ethical committee, and written informed consent was obtained from every participant's parent or legal guardian.

\section{Clinical examination}

On the day of the ultrasound, a clinical examination was performed. Height was measured using a stadiometer to the nearest $1 \mathrm{~mm}$ (Seca model CE123), and weight was measured to the nearest $0.1 \mathrm{~kg}$, using electronic scales (Dolphin). We evaluated and classified the stage of pubertal development according to Tanner puberty staging from stage 1 to 5 of breast development [15]. The presence of thelarche (onset of breast development) was the criteria used to distinguish pubertal from pre-pubertal girls. In a questionnaire, the girls reported the date of menarche, and this information was documented. Examinations were not scheduled according to their menstrual cycle. None of the girls had a history of endocrine, gynaecological, or cerebral illness.

\section{Transabdominal ultrasound}

All girls were given water to drink and were scanned with a full bladder, which served as an acoustic window. Examinations were performed by a single experienced radiologist, using a Hitachi Aloka 0.5alpha with a 5.0 MHz curvilinear probe and a 7.5-12.0 MHz linear probe. At each scan, the uterus (length from base of the cervix to the apex of the fundus, AP diameter of the fundus, and AP diameter of the cervix and thickness of the endometrium) and FCR (FCR = anterior posterior diameter of the fundus/anteroposterior diameter of the cervix) were measured. Each ovary was measured in three planes and the ovarian volume was calculated using modified formulae for the prolate ellipsoid as advocated by Sample and Lippe $\left[0.5^{\star} \mathrm{L}^{*} \mathrm{~W}^{\star} \mathrm{H}\right]$, where $\mathrm{L}, \mathrm{W}$, and $\mathrm{H}$ are the 3 maximal longitudinal, anterior-posterior, and transverse diameters, respectively [16].

\section{Statistics}

An excel spreadsheet was created from the measured data. Data were then presented as mean, standard deviation (SD), median, and 95\% confidence interval $(\mathrm{Cl})$ for each age group, Tanner stage, and pubertal status. The mean values of variables in different chronological age and of Tanner staging were compared by ANOVA and Bonferroni post hoc test. Pearson's correlation coefficient and multiple linear regression analysis were used to detect the relationship between chronological age, weight, height, and ovarian volume, uterine length, and fundo-cervical ratio, and $p<0.05$ was considered significant. STATA software for Windows version 15.0 was used for statistical analysis.

\section{Results}

A total of 130 healthy north Indian girls in the age group 5 to 16 years, who satisfied the inclusion and exclusion criteria, were enrolled in the study. Out of all the girls, 9 were excluded because their data were incomplete. The remaining 121 girls (n) were divided into groups as per their age, Tanner stage, and pubertal status. Forty-eight girls were pre-pubertal, and 73 were at various stages of puberty. Thirty (mean age -14.2 years) of the 73 pubertal girls were menstruating regularly. The mean age at menarche was 12.4 years.

The ovaries and uterus were visualised in all girls. The mean volumes of the right and the left ovary did not differ significantly in each subject; hence, the average volume of both ovaries ([right ovary + left ovary volume]/2) was calculated and used for analysis. Table I shows the uterine length, ovarian volume, and FCR in different age groups, with the total number in each group, the mean, SD, median, and 95\% confidence interval. A progressive increase in uterine length, MOV, and FCR was observed with increasing age, height, and weight. Chronological age, height, and weight were positively correlated with uterine length, MOV, and FCR ( $p<0.001$ for all). There was a significant increase in the uterine length of $4.61 \mathrm{~cm}$ at $11-12$ years to $5.47 \mathrm{~cm}$ at $12-13$ years $(p<0.001)$ and also in MOV from $0.8 \mathrm{~cm}^{3}$ at $7-8$ years to $1.3 \mathrm{~cm}^{3}$ at $8-9$ years and $2.08 \mathrm{~cm}^{3}$ at $11-12$ years to $3.03 \mathrm{~cm} 3$ at $12-13$ years $(p<0.001)$.

Table II shows the uterine length, mean ovarian volume, FCR, and endometrial thickness in relation to the Tanner stage with the number in each group, the mean, SD, and median. Figure 1 shows the progressive increase in uterine length, MOV, and FCR with puberty (increase in breast Tanner stage). A statistically significant correlation occurred between Tanner stage 1 and 2 of uterine length, MOV, and FCR ( $p<0.001$ for all).

Scan data were also divided as per pubertal status, i.e. prepubertal and pubertal. Uterine length, endometrial thickness, MOV, and FCR were smaller in girls in the pre-pubertal stage than in girls in the pubertal stage. Uterine length and MOV showed the most significant changes across this puberty status. The uterine length mean was $3.1 \mathrm{~cm}$ in pre-pubertal girls and $5.4 \mathrm{~cm}$ in pubertal girls $(\rho<0.001)$. MOV was $0.9 \mathrm{~cm}^{3}$ in pre-pubertal girls and $3.2 \mathrm{~cm}^{3}$ in pubertal girls $(p<0.001)$. FCR was 1 in pre-pubertal girls and 1.5 in pubertal girls $(p<0.001)$.

\section{Discussion}

Pelvic ultrasonography is the technique of choice for imaging normal and pathologic paediatric pelvic structures [7]. It is a non-invasive, radiation-free, inexpensive, and rapid tool 
Table I. Uterine length, MOV and FCR in relation to age $(n=121)$

\begin{tabular}{|c|c|c|c|c|c|c|c|c|c|c|}
\hline \multirow{2}{*}{$\begin{array}{l}\text { Age group } \\
\text { (years) }\end{array}$} & \multirow{2}{*}{$n$} & \multicolumn{3}{|c|}{ Uterine length (cm) } & \multicolumn{3}{|l|}{$\operatorname{MOV}\left(\mathrm{cm}^{3}\right)$} & \multicolumn{3}{|l|}{ FCR } \\
\hline & & Mean (SD) & Median & $95 \% \mathrm{Cl}$ & Mean (SD) & Median & $95 \% \mathrm{Cl}$ & Mean (SD) & Median & $95 \% \mathrm{Cl}$ \\
\hline $5-6$ & 9 & $2.64(0.29)$ & 2.55 & $2.44-2.84$ & $0.51(0.06)$ & 0.49 & $0.47-0.55$ & $0.93(0.56)$ & 0.94 & $0.89-0.97$ \\
\hline $6-7$ & 10 & $3.07(0.27)$ & 3.05 & $2.89-3.24$ & $0.58(0.08)$ & 0.55 & $0.53-0.63$ & $1.02(0.57)$ & 1.01 & $0.98-1.06$ \\
\hline $7-8$ & 11 & $3.25(0.26)$ & 3.3 & $3.09-3.41$ & $0.82(0.15)$ & 0.8 & $0.73-0.91$ & $1.09(0.13)$ & 1.1 & $1.00-1.17$ \\
\hline $8-9$ & 13 & $3.51(0.30)$ & 3.62 & $3.34-3.68$ & $1.31(0.21)$ & 1.34 & $1.19-1.43$ & $1.27(0.08)$ & 1.28 & $1.22-1.31$ \\
\hline $9-10$ & 8 & $3.75(0.40)$ & 3.86 & $3.46-4.03$ & $1.80(0.43)$ & 1.77 & $1.50-2.11$ & $1.32(0.09)$ & 1.31 & $1.26-1.39$ \\
\hline $10-11$ & 15 & $3.97(0.28)$ & 4.0 & $3.82-4.11$ & $2.02(0.22)$ & 2.06 & $1.90-2.13$ & $1.30(0.12)$ & 1.3 & $1.24-1.36$ \\
\hline $11-12$ & 9 & $4.61(0.46)$ & 4.88 & $4.30-4.92$ & $2.08(0.22)$ & 2.12 & $1.93-2.22$ & $1.31(0.11)$ & 1.36 & $1.23-1.38$ \\
\hline $12-13$ & 14 & $5.47(0.41)$ & 5.5 & $5.25-5.69$ & $3.02(0.45)$ & 3.01 & $2.78-3.26$ & $1.46(0.07)$ & 1.46 & $1.42-1.50$ \\
\hline $13-14$ & 8 & $6.14(0.29)$ & 6.16 & 5.93-6.35 & $3.51(0.35)$ & 3.42 & $3.26-3.76$ & $1.51(0.08)$ & 1.51 & $1.45-1.57$ \\
\hline $14-15$ & 12 & $6.46(0.41)$ & 6.52 & $6.22-6.69$ & $4.39(0.76)$ & 4.04 & $3.96-4.82$ & $1.68(0.16)$ & 1.71 & $1.58-1.77$ \\
\hline $15-16$ & 12 & $6.94(0.59)$ & 7.03 & $6.60-7.29$ & $4.58(0.76)$ & 4.65 & $4.14-5.02$ & $1.78(0.19)$ & 1.76 & $1.67-1.89$ \\
\hline
\end{tabular}

$\mathrm{N}$ - number of subjects; MOV - mean ovarian volume; FCR - fundo cervical ratio; SD - standard deviation; $\mathrm{Cl}$ - confidence interval

Table II. Uterine length, MOV and FCR in relation to Tanner staging $(n=121)$

\begin{tabular}{|c|c|c|c|c|c|c|c|c|}
\hline \multirow{2}{*}{$\begin{array}{l}\text { Tanner } \\
\text { staging }\end{array}$} & \multirow[t]{2}{*}{$n$} & \multicolumn{2}{|c|}{ Uterine length (cm) } & \multicolumn{2}{|c|}{ Ovarian volume $\left(\mathrm{cm}^{3}\right)$} & \multicolumn{2}{|l|}{ FCR } & \multirow{2}{*}{$\begin{array}{l}\text { Endometrial } \\
\text { thickness }(\mathrm{mm}) \\
\text { Mean }\end{array}$} \\
\hline & & Mean (SD) & Median & Mean (SD) & Median & Mean (SD) & Median & \\
\hline 1 & 48 & $3.18(0.40)$ & 3.2 & $0.93(0.42)$ & 0.78 & $1.08(0.14)$ & 1.01 & 0.6 \\
\hline 2 & 24 & $4.12(0.30)$ & 4.15 & $2.02(0.24)$ & 2.03 & $1.32(0.11)$ & 1.34 & 1.5 \\
\hline 3 & 17 & $5.36(0.35)$ & 5.3 & $2.84(0.42)$ & 2.84 & $1.43(0.05)$ & 1.42 & 2.3 \\
\hline 4 & 23 & $6.33(0.33)$ & 6.34 & $3.96(0.59)$ & 3.86 & $1.61(0.12)$ & 1.6 & 3.4 \\
\hline 5 & 9 & $7.22(0.42)$ & 7.3 & $5.06(0.53)$ & 5.24 & $1.88(0.14)$ & 1.9 & 6.1 \\
\hline$P^{\star}$ & - & $<0.001$ & & $<0.001$ & & $<0.001$ & & - \\
\hline
\end{tabular}

$\mathrm{N}$ - number of subjects; MOV - mean ovarian volume; FCR - fundo cervical ratio; SD - standard deviation

${ }^{*} p$ value is between stage 1 and 2 of tanner staging

that theoretically can be used for the distinction between prepubertal girls and girls with various forms of sexual precocity.

Precocious puberty is one of the commonest reasons for referral to a paediatric endocrine unit. With urbanisation, sedentary lifestyle, and improving nutrition, there is a sharp rise in obesity in urban India, which may also be contributing to the rising incidence of precocious puberty [17]. There is a 4 to 5 times higher preponderance of central precocious puberty (CPP) (Idiopathic mostly) in females [18]. Providing important information about internal genitalia in the female, ultrasonography could serve as a complement to the $\mathrm{GnRH}$ stimulation test, which is the gold standard for identifying the central precocious puberty $[19,20]$.

Our study is original in that we present data on healthy north Indian girls. There have been limited Indian studies previously with scarce data regarding standard values for uterine and ovarian measurements in Indian girls. 

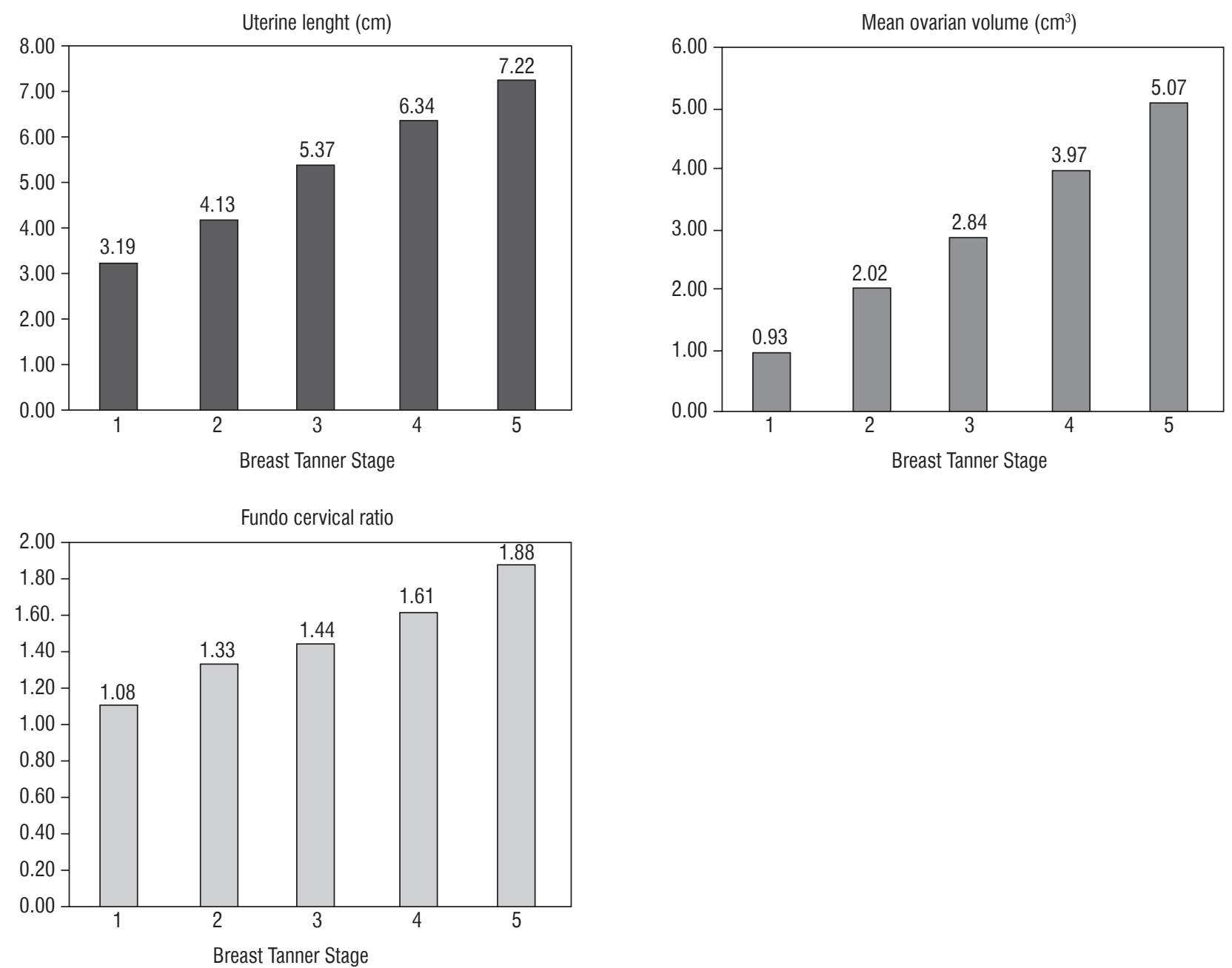

Figure 1. Uterine lenght, MOV and FCR in different stages of breast development

In our study, the ovarian volume, uterine length, and FCR were positively correlated with chronological age, weight, height, and Tanner pubertal stage, as has been described in other studies [6, 9-13].

Because the uterus is not actually shaped like an ellipse and because its shape changes over time there is a debate whether the uterine volume is better correlated with age or uterine length. Some investigators have suggested that more attention should be paid to uterine length than to uterine volume because uterine length is better correlated with age than uterine volume $[9,10,14]$, but Badouraki et al. [13] have demonstrated that uterine volume was better correlated with age than uterine length. We measured uterine length in our study and showed that it increased gradually throughout childhood with increasing age. As reported in other studies [12, 14], our study also showed a sudden significant increment in uterine length at $11-12$ and $12-13$ years $(p<0.001)$. This is probably in association with the pulsatility of $\mathrm{GnRH}$.

Some authors state that ovarian growth is influenced by age and by the onset of puberty $[5,21]$, whereas others state that it is influenced only by age $[7,22]$. In our study, the difference in ovarian volume observed in 9- to 13-year-old patients with and without thelarche shows that both age and puberty affect the ovarian size. The sudden increment in MOV was observed at $7-8$ to $8-9$ years and $11-12$ to $12-13$ years $(p<0.001)$, probably due to gonadarche.

FCR was positively correlated with age, weight, and height. Our study showed a significant increase in the FCR from 1.0 at $7-8$ years to 1.27 at $8-9$ years $(p<0.01)$. This finding could be explained by the fact that the uterus grows faster and also that the uterine body becomes wider than the cervix after 8 years of age, producing the typical adult pear-shaped uterus [14]. 
With regard to Tanner breast staging, in our study, there was a statistically significant increase in uterine length, MOV, and FCR from stage 1 to 5, i.e. all the 3 parameters increased with puberty $(p<0.001)$. This is in accordance with previous studies [3, 12, 14], but Griffin et al. [9] and Bodouraki et al. [13] did not observe any relationship with the Tanner stage, probably due to the small number of subjects in the puberty stage. There was also an increase in mean endometrial thickness with increasing Tanner breast stage.

In our study uterine length, MOV, and FCR were smaller in girls in the pre-pubertal stage than the pubertal stage. Previous studies reported that in pre-pubertal girls, the uterine length should not exceed $3 \mathrm{~cm}$ [5]. However, Badouraki et al. [13] have shown that this cut-off limit should be increased to $4 \mathrm{~cm}$ because in their study more than $97 \%$ of the uterine lengths in pre-pubertal girls were below this limit. In our study, the $95 \%$ confidence interval of 48 healthy pre-pubertal girls had a uterine length below $4 \mathrm{~cm}$. These results concur with the literature $[6,7,10,13]$. Similarly, the $95 \%$ confidence interval of pre-pubertal girls had MOV below $2 \mathrm{~cm}^{3}$. Thus, uterine length of less than $4 \mathrm{~cm}$, MOV of less than $2 \mathrm{~cm}^{3}$, and FCR less than or equal

\section{References}

1. Parent S, Tillman G, Jule A, Skakkebaek NE, et al. The timing of normal puberty and the age limits of sexual precocity: variations around the world, secular trends, and changes after migration. Endocrine Reviews 2003; 24: 668-693.

2. Bridges NA, Cooke A, Healy MJR, Hindmarsh PC, et al. Growth of the Uterus. Arch Dis Child 1996; 75: 330-331.

3. Garel L, Dubois J, Grignon A, et al. US of the pediatric female pelvis: a clinical perspective. Radio-Graphics 2001; 21: 1393.

4. Holm K, Mosfeldt Laursen E, Brocks V, et al. Pubertal Maturation of the internal genitalia: an ultrasound evaluation of 166 healthy girls. Ultrasound Obstet Gynecol 1995; 6: 175-181.

5. Sample WF, Lippe BM, Gyepes MT. Gray-scale ultrasonography of the normal female pelvis. Radiology 1977; 125: 477-483.

6. Ivarsson AS, Nilsson KO, Persson P-H. Ultrasonography of the pelvic organs in prepubertal and postpubertal girls. Arch Dis Child 1983; 58: 352-354.

7. Orsini LF, Salardi S, Pilu G, et al. Pelvic organs in premenarcheal girls: real-time ultrasonography. Radiology 1984; 153: 113-116.

8. Giorlandino C, Gleicher N, Taramanni C, et al. Ovarian development of the female child and adolescent: I. Morphology. Int J Gynaecol Obstet 1989; 29: 57.

9. Griffin IJ, Cole TJ, Duncan KA, et al. Pelvic ultrasound measurements in normal girls. Acta Paediatr 1995; 84: 536-543.

10. Herter LD, Golendziner E, Flores JA, et al. Ovarian and uterine sonography in healthy girls between 1 and 13 years old: correlation of findings with age and pubertal status. AJR Am J Roentgenol 2002; 178: 1531

11. Seth A, Agarwal A, Sandesh K, et al. Pelvic ultrasonography in pubertal girls. Indian J Pediatr 2002; 69: 869-872. to 1 were specific for the identification pre-pubertal girls and can be used for diagnosis of the early stage of puberty.

Our limitations include the fact that ours was a cross-sectional study done at a single centre in a small sample; hence, the data cannot be generalised to the whole population. For this, larger longitudinal studies consisting of individuals from different geographical regions are required. Bone age is the best determinant for uterine and ovarian parameters, but due to some limitations in our institute, we did not correlate bone age with uterine and ovarian parameters.

\section{Conclusions}

The present study demonstrated that there was a continuous increase in the size of the uterus and ovaries from 5 to 16 years of age, and also with the puberty stage. The normative ultrasound data, including reference charts of uterine and ovarian parameters in north Indian girls generated in our study, would be useful for screening girls with abnormalities of pubertal development.

12. Khadilkar W, Khadilkar AV, Kinare AS, et al. Ovarian and uterine ultrasonography in healthy girls between birth to 18 years. Indian Pediatr 2006; 43: 625.

13. Badouraki M, Christoforidis A, Economou I, et al. Sonographic assessment of uterine and ovarian development in normal girls aged 1 to 12 years. J Clin Ultrasound 2008; 36: 539.

14. Razzaghy-Azar M, Ghasemi F, Hallaji F, et al. Sonographic measurement of uterus and ovaries in premenarcheal healthy girls between 6 and 13 years old: correlation with age and pubertal status. J Clin Ultrasound 2011; 39: 64-73.

15. Tanner JM. Growth at adolescence, 2nd edn. Blackwell, Oxford 1962.

16. Lippe BM, Sample WF. Pelvic ultrasonography in paediatric and adolescent endocrine disorders. J Pediatr 1978; 92: 897-902.

17. KhadilkarVV, Khadilkar AV. Prevalence of Obesity in Affluent School Boys in Pune. Indian Pediatr 2004; 41: 857-858.

18. Desai M, Colaco MP, Choksi CS, et al. Isosexual precocity: The Clinical And etiologic profile. Indian Pediatr 1993; 30: 607-623.

19. deVries L, Horev G, Schwartz M, et al. Ultrasonographic and clinical parameters for early differentiation between precocious puberty and premature thelarche. Eur J Endocrinol 2006; 154: 891.

20. Garibaldi L. Gonadotropin-dependent precocious puberty. In: Kliegman RM, Behrman RE, Jenson HB, et al. Nelson Textbook of Pediatrics, 18th edition. WB Saunders (Elsevier), Philadelphia 2007; 2309-2311.

21. King LR, Siegel MJ, Solomon AL. The usefulness of ovarian volume and cysts in female isosexual precocious puberty. J Ultrasound Med 1993; 12: 577-581.

22. Salardi S, Orsini LF, Cacciari E, et al. Pelvic ultrasonography In premenarcheal girls: relation to puberty and sex hormone concentrations. Arch Dis Child 1985; 60: 120. 